\title{
Microscopic Simulation of Pedestrian Traffic
}

Fredrik Johansson 


\section{Microscopic Simulation of Pedestrian Traffic}

Fredrik Johansson

Linköping Studies in Science and Technology. Dissertations, No. 1767

Copyright (c) 2016 Fredrik Johansson, unless otherwise noted

ISBN 978-91-7685-756-4

ISSN $0345-7524$

Printed by LiU Tryck, Linköping, Sweden 2016 


\section{Abstract}

There has recently been a renewed interest in planning for pedestrian traffic, primarily in connection to public transport interchange stations, since these are important for public transport to constitute an attractive alternative to car usage. This thesis concerns microscopic simulation of pedestrian traffic, which is a promising tool for analyzing and predicting the traffic situation in a given pedestrian facility; particularly powerful when the traffic is congested. Important applications of microscopic simulation include comparison of possible infrastructure designs such as proposed interchange stations, and evaluations of various traffic management solutions, for example information systems.

The purpose of this thesis is to advance the capabilities of pedestrian microsimulation toward a level at which it can be reliably applied for quantitative analysis by practitioners in the field. The work is based on an established microscopic model of pedestrian dynamics, the Social Force Model (SFM), and the advances are made in a number of different areas.

To be able to evaluate and compare simulated traffic situations suitable performance measures are needed. A set of local performance measures are proposed that quantifies the local delay rate density and estimates the discomfort perceived by the pedestrians.

The SFM is extended to include waiting pedestrians through the introduction of a waiting model, demonstrated to be stable and free from oscillations. The inclusion of waiting pedestrians in the model is critical for accurate modelling of public transport interchange stations, where 
large groups of waiting pedestrians may hinder passing pedestrians if the design of the station is poor.

The relaxation time of the adaptation to the preferred velocity is an important parameter in force based models of pedestrian traffic since it affects several behaviors of the simulated pedestrians, two of which are linear acceleration and turning movements. A comparison of observations of accelerating pedestrians reported in the literature and new observations of turning pedestrians indicates that no value of the relaxation time can give model behavior consistent with both sets of observations. This indicates that modifications of the model is needed to accurately reproduce the observed behavior.

An important input to simulations is the preferred speed of the simulated pedestrians. The common assumption that the preferred speed distribution at a location does not vary during the day is tested through observations of pedestrian traffic at Stockholm Central Station. The results demonstrate that the preferred speeds are lower in the afternoon than in the morning, implying that the preferred speed should be treated as a source of uncertainty when applying pedestrian microsimulation.

Finally, a sensitivity analysis of a simulation of the lower hall of Stockholm Central Station is performed to find the most important sources of uncertainty in the model predictions, given the available data. The results indicate that the uncertainty related to calibration is the largest of the considered potential error sources. 


\section{Populärvetenskaplig sammanfattning}

Nyligen har intresset för planering för gångtrafik ökat, främst i samband med bytespunkter för kollektivtrafik, eftersom dessa är viktiga för att kollektivtrafiken ska utgöra ett attraktivt alternativ till bilanvändning.

Denna avhandling behandlar mikroskopisk simulering av gångtrafik, vilket är simulering som beskriver enskilda fotgängare och dessas interaktion med varandra och med infrastrukturen. Vid trängsel är gångtrafik mycket komplex och flödena svårförutsägbara på grund av den stora frihet fotgängare har att anpassa sig till den rådande situationen. Trots detta utgör mikroskopisk gångtrafiksimulering ett lovande verktyg för att analysera trafiken, göra prognoser, samt för att jämföra olika designalternativ, till exempel av olika föreslagna bytespunkter för kollektivtrafik.

Avhandlingens syfte är att förbättra funktionaliteten av mikroskopisk gångtrafiksimulering mot en nivå där den på ett pålitligt sätt kan användas som ett verktyg för kvantitativ analys av infrastruktur för gångtrafik av användare i branschen.

Arbetet tar sin utgångspunkt i en etablerad mikroskopisk modell, den så kallade Social Force Model (SFM). Mjukvara baserad på denna modell kan användas för att simulera hur trafiken kommer att te sig beroende på hur infrastruktur, som till exempel en bytespunkt i kollektivtrafiken, utformas. Den här typen av mjukvara används i Sverige 
främst av trafikkonsultföretag på uppdrag av infrastrukturägaren.

För att möjliggöra utvärdering av infrastruktur baserat på simulering presenteras en uppsättning prestandamått som beskriver hur mycket fotgängarna fördröjs och hur obekväm en trafiksituation kan upplevas, samt var i det simulerade området problemen finns.

För att möjliggöra utvärdering av infrastruktur där det är vanligt att många fotgängare står och väntar, till exempel bytespunkter för kollektivtrafik, föreslås en modell för hur väntande beter sig och reagerar på passerande fotgängare. Den föreslagna modellen visas uppföra sig på ett matematiskt sunt sätt, vilket är en nödvändighet för att kunna använda modellen eftersom den inte kan testas i alla möjliga situationer som kan uppstå under en simulering.

SFM har ett flertal parametrar som behöver anpassas så att de simulerade fotgängarna beter sig som riktiga fotgängare. En av dessa parametrar är relaxationstiden, som i princip beskriver hur snabbt en stillastående fotgängare accelererar upp till sin önskade fart. På grund av modellens enkelhet så påverkar relaxationstiden även hur skarpa svängar fotgängaren kan göra. Genom en jämförelse av tidigare studier av accelererande fotgängare och nya observationer av svängande fotgängare demonstreras att det inte går att välja ett värde på relaxationstiden som gör att modellens beteende är konsistent med båda uppsättningarna observationer. Detta indikerar att det finns ett behov av att modifiera modellen för att öka modellens noggrannhet.

En egenskap hos fotgängare som är viktig att representera korrekt i mikroskopiska modeller är deras önskade fart, det vill säga hur fort de skulle föredra att gå om det inte var någon trängsel. För att mäta den önskade farten kan man observera hur fort folk går när det är så lite trafik att fotgängarna kan röra sig helt oberoende av varandra; man antar då att de går med sin önskade fart. Situationer som är intressanta att simulera är situationer med en betydande trängsel, och dessa situationer uppträder i regel vid andra tidpunkter på dygnet än situationer med lite trängsel. Därför uppstår frågan om de önskade farter som observerats vid lågtrafik kan användas för simulering av högtrafik vid en annan tid på dygnet. Hur vet vi att folks önskade fart inte ändrar sig 
under dagen? Denna fråga undersöks genom jämförelser av önskade farter observerade på morgonen och eftermiddagen på Stockholm centralstation. Jämförelsen indikerar att de önskade farterna är lägre på eftermiddagen, vilket får konsekvenser för hur noggranna resultat vi kan förvänta oss av modellen.

Slutligen undersöks hur känslig en simulering av nedre hallen på Stockholms centralstation är för ett antal potentiella felkällor, till exempel osäkerhet $\mathrm{i}$ indata och parametervärden. Undersökningen pekar mot att kalibreringen av modellen är mycket viktigare än de övriga övervägda felkällorna, vilket indikerar att vidare forskning inom kalibrering behövs. 



\section{Acknowledgments}

The research presented in this thesis has been carried out at the Division of Communication and Transport Systems (кTS) at Linköping University and at The Swedish National Road and Transport Research Institute (VTI). The research has been sponsored by the Swedish Transport Administration through the Center for Traffic Research (стR). Linköping municipality, Östgötatrafiken, and Jernhusen have supported the research with their expertise and data.

My supervisors, Jan Lundgren, Andreas Tapani, and Anders Peterson, deserve credit for guiding me through my research studies. It has been a true luxury to get advise and comments from three, often somewhat different, angles.

I'm grateful for the opportunity to work at both KTS and vTI; the administrative staff have made the bureaucracy manageable, and colleagues have made these years both interesting and entertaining. In particular the graduate student community at KTs, both those still present and those who left us, have been very friendly and supportive; thank you all for being who you are!

I would specifically like to thank Joakim Ekström and Carl Henrik Häll, for always being supportive and for showing not only that it's possible to graduate, but also that there is an afterlife. But most of all colleagues I would like to thank my office and study partner Ellen Grumert, who's always been there. Thank you for everything!

This thesis would not exist if it wasn't for Winne Daamen and Serge Hoogendoorn, who welcomed me to Delft for a couple of months of in- 
tense research. I could not have continued after my licentiate without some supervision by experts in the field of pedestrian simulation. I also would like to thank the extremely friendly $\mathrm{PhD}$ students at the Department of Transport and Planning for making my stay in Delf more than just hard work.

I owe my friends and family much more than a small acknowledgement, but for now: Thank you for all your support, both past and present.

Above all, thank you Sara and Astrid, no words are sufficient to express my gratitude.

Göteborg, May 2016 Fredrik Johansson 


\section{Contents}

$\begin{array}{lll}\text { Abstract } & \text { iii }\end{array}$

Populärvetenskaplig sammanfattning $\quad$ V

Acknowledgments $\quad$ ix

1 Introduction 1

2 Force based pedestrian modeling 5

2.1 Model structure $\quad 6$

2.2 The Social Force Model 8

2.3 A Pedestrian Traffic Simulation Platform 13

$\begin{array}{ll}2.4 & \text { Calibration of the SFM } \\ & 16\end{array}$

3 The present thesis 21

3.1 Contributions $\quad 22$

3.2 Delimitations 23

3.3 Paper summaries $\quad 24$

3.4 Future research 30

Bibliography 35

Included papers $\quad 41$ 



\section{Chapter 1}

\section{Introduction}

Pedestrian traffic is an essential part of the traffic system; practically all trips include some walking, at least to and from the main mode of transport of the trip. If the main mode is public transport the trip also often includes a transfer between vehicles, resulting in a short walk also at the interchange station. Also the pure walking trips are important; a large number of short walking trips from one block to another is made in the city centers.

The last decades, the importance of walking as a mode of transport has started to become recognized, much due to environmental problems caused by car usage in combination with continued urbanization. Well planned pedestrian infrastructure, primarily in connection to public transport access points and in the city centers, could help increase the attractiveness of alternatives to car usage.

Planning for pedestrian traffic includes many aspects, from providing direct walkways between popular destinations, and safety from nearby motorized traffic, to planning efficient flows at crowded public transport stations, shopping malls, arenas, etc. This thesis is focused on pedestrian traffic where the pedestrian congestion is the dominating problem. Pedestrian traffic here refers to walking with the purpose of transportation, i.e., not walking for leisure or exercise, but for accessing 
some utility at the destination.

The problem of designing pedestrian infrastructure is both important and nontrivial, which can be seen by considering the problem of designing a public transport interchange station. Many of the trips made by public transport in a city either starts or ends at the central station, or include transfer there. The functionality of the station thus affects the whole public transport system, which needs to be efficient and comfortable to be an attractive alternative to private car. To enable a well functioning station, with efficient and comfortable transfers, short distances between the platforms are needed. This leads to a compact design of the station, with as little extra space as possible. The need for small stations is further emphasized by the high price of land in the city centers, making small stations economically favorable.

The problem is thus clear: we have a small station to get efficient and comfortable transfers, but a large number of public transport travelers, which in the small space leads to pedestrian congestion reducing the traffic efficiency and comfort at the station. To obtain a smart design that keeps walking distances short while also providing sufficient space for efficient flows, it is necessary to accurately predict the pedestrian traffic at the station, so that different designs can be evaluated and compared before the station is built. Such predictions of the pedestrian traffic are possible through mathematical modeling and simulation.

Designing a public transport interchange station, is here and frequently throughout this thesis, used as an example of a possible application. It may be the most important application, but the reasoning and results are generalizable to any facility with significantly congested pedestrian traffic.

There is a number of ways to mathematically model pedestrian traffic. These can be categorized based on how the traffic is represented in the model, from macroscopic to microscopic models. Macroscopic models are based on some kind of continuity assumption, treating the traffic as a continuous flow, only modeling the average characteristics. Microscopic models, on the other hand, explicitly represent each pedestrian and its interactions with other pedestrians and the infrastructure. This 
thesis concerns microscopic models within the group of models known as simulation models, that is, those that explicitly model the dynamic evolution of the traffic situation in time.

In the process of designing or evaluating a pedestrian facility it is useful to be able to not only evaluate the facility as a whole, but also to get detailed information about problematic areas and the nature of the potential problems. Such information can help to deduce the cause of the problem and assist in finding better designs. For this to be possible, the model needs to represent both the pedestrian traffic and the infrastructure at a high level of detail. Thus, microscopic simulation is a suitable modeling approach for this type of problem. Microscopic simulation also enables explicit representation of the diversity of the pedestrian population in the model; people have different destinations, preferences regarding routes, purposes of being at the facility, preferred walking speeds, etc.

The purpose of this thesis is to advance the capabilities of pedestrian microsimulation toward a level at which it can be reliably applied for quantitative analysis by practitioners in the field. The strategy to achieve this purpose is to focus on addressing some of the most important shortcomings of one the most widely used microsimulation models, the Social Force Model (SFM). This choice of model is primarily motivated by that it is well studied and by its availability for practitioners through commercial software, which enable as direct applicability of the results as possible.

The main contributions of this thesis are: local performance measures of pedestrian traffic, providing information regarding the simulated traffic at a relevant scale; a model of waiting pedestrians, enabling the simulation of waiting groups often present at public transport stations; deeper understanding of the role of the relaxation time parameter, providing insights facilitating further improvements and calibration of the model; a method for estimating the preferred speed distribution of pedestrians at a public transport station; and finally a sensitivity analysis in a simplified case. Collectively, these contributions increase the understanding of force based simulation of pedestrian traffic in general, 
and the SFM in particular. They also enable more accurate simulations. The remainder of this thesis is organized as follows. An introduction to force based pedestrian simulation modeling is given in Chapter 2, introducing the structure of force based simulation models, and reviewing the SFM. The chapter also introduces the simulation platform, the Pedestrian Traffic Simulation Platform (PTSP), developed as part of the research underlying this thesis and utilized to perform simulations in most of the studies included in the thesis. Calibration of this type of models is briefly discussed. The chapter presents the context in which the present thesis should be viewed. The purpose, contributions, and delimitations of the research presented in this thesis are specified in Chapter 3. Also summaries of the included papers and a discussion of future research directions are included in the chapter. Finally, five papers are included. 


\section{Chapter 2}

\section{Force based pedestrian modeling}

The simulation model applied and further developed in this thesis, the Social Force Model (SFM), can be classified as a force based microscopic model. In models of this category a simulated pedestrian reacts to stimuli in its environment by adjusting its acceleration. The stimuli can be a too short distance to, or an imminent risk of collision with, another pedestrian or an obstacle, etc.

The characteristic simplifying assumption of force based models is that the reaction of a pedestrian to a set of stimuli is the sum of the reactions to the individual stimuli, as if the pedestrian was affected by a force caused by each stimulus. This assumption makes the model similar to a physical model of particles, making it possible to take advantage of knowledge from such systems when constructing, analyzing and solving the model.

However, this assumption is of course a simplification; in some situations the reaction of a pedestrian is not just the sum of its reactions to the individual stimuli, instead the stimuli may combine nonlinearly to produce a reaction. The individual reactions, on the other hand, are highly nonlinear functions of the states of the pedestrian and its sur- 
rounding, making for example the stimulus of an imminent collision completely outweigh most other stimuli.

Force based models of pedestrian traffic originates at least as far back as Hirai and Tarui (1975), who used a force base model to simulate the movement of a panicking crowd evacuating a building. Later the force concept was, independently from Hirai and Tarui (1975), proposed by Gipps and Marksjö (1985), who noted the utility of microscopic pedestrian models to simulate regular pedestrian traffic. Also the implementation in terms of spatial and temporal discretization is discussed, noting that spatial discretization is necessary to reach acceptable computational times.

The requirement of computational efficiency was no longer as pressing when Helbing and Molnár (1995) proposed the SFM, due to the rapid increase of available computational capacity. In addition to proposing a force based model with continuous space representation, they also demonstrated that the model replicates observed collective phenomena, such as dynamic lane formation, bottleneck oscillations, and later also stripe formation in intersecting flows, which were not explicitly considered in the construction of the model. This success of the SFM, in combination with an increasing interest for environmentally friendly modes of transport and the rapid increase in computational power, have led to a wide variety of force based models and extensions to the SFM.

\subsection{Model structure}

Pedestrian behavior can be seen as a three level process, as discussed by Hoogendoorn and Bovy (2004) and Daamen (2004), in a similar way as the driving task discussed by Michon (1985). The levels correspond to different spatiotemporal scales, ranging from the immediate surroundings of the pedestrian and the next fractions of a second, to the whole pedestrian facility and the duration of the trip, as well as different levels of consciousness, ranging from instinctive to premeditated behavior. This three level view of the behavior is reflected in the structure of force based simulation frameworks. 
The strategical level, corresponding to activity planning, is global in scale, covering the whole pedestrian trip. It consists of highly conscious, premeditated decisions, of which many can be taken even before starting the trip, based on previous experiences or information gathered in preparation for the trip. High level choice of preferred route between the planned activities can be included at this level, at least for pedestrians with much experience of the facility.

At the tactical level the decisions taken at the strategical level are adopted to the present conditions, that is, dynamical route choice and adjusting the activity plan. It concerns a lower spatiotemporal scale, limited by the ability of the pedestrian to perceive the conditions to react to, and the decisions are less premeditated than on the strategical level, being induced by the conditions and taken on the fly.

Finally, the operational level amounts to trying to follow the route choice of the upper levels as closely as possible, while still keeping a comfortable distance to other pedestrians and obstacles. This level is almost completely instinctive, at least for pedestrians who are used to dense pedestrian traffic, and only the immediate surroundings of the pedestrian is considered.

Force based models, such as the SFM, controls the behavior of simulated pedestrians at the operational level. It takes as input the preferred velocity of the pedestrian and produces the actual movements of the pedestrian in terms of its acceleration. From the perspective of the operational force based model, the preferred speed is external to the model, either given as input data, or passed as output from the model of the tactical level of the pedestrian behavior.

If a simple static route choice is used at the tactical level, a reasonable alternative is to let the simulated pedestrians prefer the shortest path to their destination. Along this path the preferred velocity of the simulated pedestrian is given by the tangent of the path scaled with a, usually individual, preferred speed. However, since dynamical events at the operational level may cause the simulated pedestrian to deviate from its preferred path, the tactical model must be able to provide a preferred velocity also away from the preferred path, at any point 
reachable by the pedestrian. This is usually achieved by calculating the shortest path from every point in the walkable area to the destination, resulting in a vector field of preferred directions defined on the walkable area. This method can be generalized to more advanced route choice models, such as dynamic route choice based on the distribution of pedestrians or estimated travel times, with the difference that, in the dynamic models, the field needs to be recalculated frequently, while in the static case the field can be calculated once, in advance of the simulation.

As is evident from the presentation of the levels above, there are several decisions that can be taken on either one of the levels depending on the specific circumstances. Moreover, due to the diversity of the pedestrian population, individuals may take the decisions more or less consciously. For example, a pedestrian not used to congestion may think really hard and have a deliberate tactic of how to avoid colliding with other pedestrians. Thus, the behavioral levels are here treated rather approximately to facilitate a discussion of the model structure rather than constituting a disjoint categorization with well defined bounds.

\subsection{The Social Force Model}

Many versions of the SFM have been developed since its proposal by Helbing and Molnár (1995), and there is also a number of closely related models. Most of them define the force representing the desire of pedestrian $i$ to approach the destination as

$$
\mathbf{F}_{i}=\frac{1}{\tau}\left(\mathbf{v}_{i}^{\mathrm{p}}-\dot{\mathbf{x}}_{i}\right),
$$

where $\mathbf{v}_{i}^{\mathrm{p}}$ is the externally given preferred velocity, $\mathbf{x}_{i}$ is the position, and $\tau$ is the relaxation time determining the time scale of the adaptation to the preferred velocity.

However, there are models that include a driving force differing from Equation (2.1). One example is the model presented by Hoogendoorn and Bovy (2003), which differentiates between longitudinal and 
lateral acceleration and also takes into account the rate of change of the preferred velocity in space. However, to the best knowledge of the author of this thesis, this much more complicated model has not been implemented and its behavior remain untested.

The social interaction force $\mathbf{F}_{i j}$ between pedestrians $i$ and $j$ is given as the spatial gradient of a potential, $V_{i j}$, of the form

$$
V_{i j}=F \sigma e^{b / \sigma},
$$

where $F$ and $\sigma$ are model parameters describing the strength and range scale of the force, respectively, and the shape of the potential, $b$, is a function of the position of the affected pedestrian relative to the affecting pedestrian and the velocity of the affecting pedestrian or the relative velocity of the pedestrians. In the original model the shape is defined so that the equipotential curves of the interaction potential constitutes ellipses with one focal point at the position of the pedestrian and the other at the anticipated position of the pedestrian a certain anticipation time into the future. This construction is motivated by that pedestrians are assumed to avoid not only the current position of the affecting pedestrian, but also give room for its next few steps. A special case of this shape of the potential is the circular specification obtained by setting the anticipation time to zero, which gives a much simpler and computationally less expensive model.

An alternative specification of the shape is given by A. Johansson et al. (2007), who specifies a potential that depends on the relative velocity of the interacting pedestrians instead of just the velocity of the affecting pedestrian. This specification has the advantage over the original that pedestrians that approach each other are more strongly repelled than pedestrians who do not.

There are also other ways of modeling the anticipatory behavior of pedestrians. Zanlungo et al. (2011) present a model in which the time at which the pedestrians are closest to each other, assuming linear extrapolation, is used to calculate the interaction force. This reduces the number of parameters of the model by one, but the additivity of the forces is lost. 
The basic assumption of force based models is that the reaction of a pedestrian, in the form of an acceleration, to a number of stimuli is the sum of the reactions to the individual stimuli. The acceleration pedestrian $i$ will try to achieve in response to stimuli in its environment is given by

$$
\mathbf{a}_{i}=\sum_{j}\left(w\left(\varphi_{i j}\right) \mathbf{F}_{i j}+\mathbf{F}_{i j}^{\mathrm{ph}}\right)+\sum_{o} \mathbf{F}_{i o}^{\mathrm{ob}}+\mathbf{F}_{i}^{\mathrm{rnd}} .
$$

Here, $\mathbf{F}_{i j}^{\mathrm{ph}}$ is a physical force between pedestrians to model any physical contact, $\mathrm{F}_{i o}^{\text {ob }}$ is a force repelling the pedestrian from obstacle $o$, similar to the force between pedestrians, and $\mathbf{F}_{i}^{\mathrm{rnd}}$ is a random force to include deviations from the usual behavior. The social interaction forces $\mathbf{F}_{i j}$ are weighted by anisotropic factors, $w\left(\varphi_{i j}\right)$, ensuring that pedestrians are affected less by what happens behind them compared to what happens within their field of view. Also this anisotropy can be modeled in several different ways.

The original model by Helbing and Molnár (1995) assumes that the weight is one when the angle between the looking direction of the affected pedestrian and the direction to the affecting pedestrian is smaller than a certain threshold, and a smaller constant when the angle is larger than the threshold. This model has the disadvantage that the force becomes discontinuous at the threshold angle, potentially giving abrupt behavioral changes of a simulated pedestrian when another pedestrian enters its field of view. The model by Hoogendoorn and Bovy (2003) instead includes the anisotropy in the shape of the interaction potential, $b$, but still assumes a similar threshold behavior. Another approach to the anisotropy is taken by Helbing et al. (2005), who assume a weight continuously decreasing as the angle between the looking direction of the affected pedestrian and the direction to the affecting pedestrian increases. A continuously decreasing influence like this can be motivated by considering that pedestrians move their head as they walk, thus, the field of view is not fixed straight forward but occasionally includes things at a rather wide angle from the main looking direction.

The above discussion of the anisotropic weights include references to the looking direction of the simulated pedestrians. There are two 
natural alternative ways of defining the looking direction: either the direction of motion of the simulated pedestrian, or the direction of the preferred velocity. The definition used in the original model, and arguably the most suitable, is to equate the looking direction and the direction of the preferred velocity. The alternative, that is to assume that the pedestrian always looks in the direction of movement, may seem natural but implies several unrealistic behaviors. First, it implies that a pedestrian cannot sidestep, but always turns to avoid other pedestrians. And secondly, since the model does not include any rotational inertia, these frequent rotations will be instantaneous, posing serious stability problems in addition of being severely unrealistic.

However, using the preferred direction as looking direction does not completely eliminate the inertia free rotations since the preferred direction in general is allowed to change discontinuously in most types of route choice models. A typical example is if the shortest path navigation is used; if the walkable region is not simply connected, but has holes, there will be curves in the walkable region across which the preferred direction discontinuously changes. This is important to be aware of when interpreting the output of simulations, so that predicted effects along these curves are interpreted with caution.

This has been carefully handled in the waiting model proposed in this thesis, through the separation of the looking direction and the preferred direction for waiting pedestrians, so that no discontinuous change in the looking direction occurs at the preferred waiting position, see Paper II for details. However, a small discontinuous change generally occur when the pedestrian transitions from the walking state to the waiting state; this can only happen once per pedestrian and waiting period, but is still important to keep in mind when analyzing the simulation outputs.

The original SFM did not include a physical interaction force, and did not include the physical size of the pedestrians, instead Helbing and Molnár (1995) argued that the social interaction force will keep the pedestrians separated so that the addition of a physical force would have negligible qualitative effects on the behavior of the simulated traf- 
fic.

However, the detailed specification of the physical interaction force, or inclusion of the physical size of pedestrians in some other way, may be important for the accuracy at high densities. Helbing et al. (2000) propose a physical interaction force which includes both a normal component and a tangential friction component, and include the physical size of pedestrians into the social interaction force. This is motivated by the application area of simulating evacuation of buildings under panic conditions.

Such detailed modeling of the physical interaction is hardly necessary for simulation of normal traffic conditions. Helbing et al. (2005) also include the physical size of pedestrians into the social interaction force, but propose a simpler specification of the physical force similar to the social interaction force but without the anisotropic weights, and with different values of the parameters.

One important effect of including an isotropic physical force is that the pedestrians become more 'pushy', that is, they will strongly affect pedestrians in front of them even if those are facing away from them. This implies that a pedestrian with a high preferred speed may, depending on the exact specification of the forces, be able to push through a group of slower pedestrians walking in the same direction.

A reasonable assumption is that pedestrians have a maximum acceptable speed, $v_{i}^{\max }$, that they never exceed. In the original model this speed limit is enforced by assuming that

$$
\dot{\mathbf{x}}_{i}=\frac{\mathbf{v}_{i}}{v_{i}} \min \left\{v_{i}, v_{i}^{\max }\right\}
$$

where $\mathbf{v}_{i}$ is given by

$$
\dot{\mathbf{v}}_{i}=\mathbf{a}_{i},
$$

and initial conditions. This way of enforcing a maximum speed, which is not included in the later specification by Helbing et al. (2000), introduces a sort of additional inertia when the speed of a pedestrian is about to decrease from $v_{i}^{\max }$, and implies that $\mathbf{a}_{i}$ only is the actual acceleration of the pedestrian when the speed is below $v_{i}^{\max }$. 


\subsection{A Pedestrian Traffic Simulation Platform}

The development and investigation of models of pedestrian traffic are dependent on the availability of a transparent and modifiable simulation platform. When the research presented in this thesis was initiated in 2010, there was, to the best knowledge of the author, no such platform available. The development of the Pedestrian Traffic Simulation Platform (PTSP) was therefore initiated.

To facilitate future modifications, for example changing to another specification of the SFM or to another operational model altogether, an object oriented approach and modular design was chosen. At this initial stage, a graphical user interface was judged to be desirable, both for visualizing simulations and to facilitate for others to use the software. These requirements led to the choice to develop the software in the $\mathrm{C}++$ programming language (Stroustrup, 1984, 2013) and use the Qt framework (The Qt Company Ltd., 2016) for the graphical user interface and visualization. The alternative approaches, to either use an existing commercial product, or develop within some general purpose simulation framework, were rejected to not in any way limit the flexibility and constrain future development.

The initial version of the software is documented in Paper I and by F. Johansson (2013), where the latter report includes both a full description of the model as well as a detailed description of the implementation. The PTSP has later been expanded with features needed for the remaining papers included in this thesis, while more or less deprecating the graphical user interface in favor of command line operation more suitable for automation by scripting.

In all papers included in this thesis, the simulations have been performed with the PTSP, except for Paper IV, which only includes a very special type of simulations as part of a calibration procedure. Since the PTSP plays such a central part in the research underlying this thesis, an overview of the components of the implemented model is given in this chapter, organized according to the hierarchy described in Section 2.1. 
For a full description including implementation details, see F. Johansson (2013).

The activity plans of the simulated pedestrians are viewed as input data to the PTSP, and are modeled using origins, where the simulated pedestrians are created; destinations, to which they are going; and paths, consisting of an ordered set of destinations.

Origins and destinations are rectangular regions of the walkable area. Origins create simulated pedestrians with time gaps and locations from a given distribution. At creation, a pedestrian is assigned a path according to probabilities specified for the origin, and starts walking toward the first destination on its path. The pedestrian is initialized with a velocity equal to its preferred velocity, given by its first destination and the route choice model.

When a pedestrian enters the next destination on its path, it will either start waiting, or, if the destination is the last on the path, be removed from the simulation. If the destination is not the last on the path of the pedestrian, it is assigned a waiting time, and starts obeying the waiting model described in Paper II.

A path is just a sequence of destinations, not including the origins; a specified path can therefore be assigned to pedestrians created at different origins.

In summary, the implemented activity planning is completely static and independent of the current situation and the demand is specified as a set of origins and paths consisting of destinations.

The route choice model that guides the pedestrians toward the next destination on its path is a simple shortest path algorithm. That pedestrians follow the shortest path is of course a simplification; pedestrians not familiar with the facility may choose significantly longer paths, and pedestrians may also try to avoid congestion to get to their destination in a shorter time, therefore deviating from the shortest path. There are also other reasons for deviating from the shortest path, such as preferences for certain walking environments: protection from or exposure to weather, preferable views, certain areas may be perceived as more or less safe, etc. 
Large scale deviations from shortest path behavior can be modeled by additional intermediate destinations. This method is, however, limited to observed deviations, and thus lacks any predictive power regarding route choice. Thus, shortest path route choice, with potential for this type of hard coded deviations, is suitable only when using the simulation to compare alternatives that differ in such a way that route choice is unlikely to differ.

The problem of finding the shortest path to destination $d$ in the walkable area, $\Omega \subset \mathbb{R}^{2}$, can be formulated as a boundary value problem including the eikonal equation on $\Omega$. Let $\phi_{d}(\mathbf{x})$ be the length of the shortest path in $\Omega$ connecting $\mathbf{x} \in \Omega$ and the destination area $\Delta_{d}$, then the boundary value problem can be formulated as

$$
\begin{aligned}
\left|\nabla \phi_{d}(\mathbf{x})\right| & =C(\mathbf{x}), \\
\phi_{d}(\mathbf{x}) & =0, \mathbf{x} \in \Delta_{d},
\end{aligned}
$$

with the right hand side given by

$$
C(\mathbf{x})= \begin{cases}1, & \mathbf{x} \in \Omega, \\ M, & \mathbf{x} \in \Omega^{c},\end{cases}
$$

where $M$ is a large constant. The route choice of a pedestrian is then determined by the preferred velocity, given by

$$
\mathbf{v}_{i}^{\mathrm{p}}(\mathbf{x})=-v_{i}^{\mathrm{p}} \frac{\nabla \phi_{d}(\mathbf{x})}{\left|\nabla \phi_{d}(\mathbf{x})\right|}, \quad i \in \mathcal{I}_{d},
$$

where $\mathcal{I}_{d}$ is the subset of pedestrians with destination $d$, and $v_{i}^{\mathrm{p}}$ is the preferred speed of the pedestrian. The route choice of a pedestrian to its next destination is thus given by the preferred velocity of the pedestrian, defined at each point of the walkable area.

The boundary value problem (2.5) is solved using the Fast Marching Method (FMM) by Sethian (1996), which is similar to Dijkstra's algorithm (Dijkstra, 1959), except that it does not rely on a network representation of the walkable area.

An alternative to the eikonal approach would be to define a visibility graph on the walkable area and find the shortest path on the 
graph (Lozano-Pérez and Wesley, 1979). This would be computationally superior in comparison to the chosen approach for a polygonal walkable area. However, the chosen approach can be extended to include an additional cost of walking, in addition to the distance, continuously varying in the walkable area, by letting $C(\mathbf{x})$ vary in space. In this way preferences for certain types of areas can be modeled. This walking cost field can also be dynamically updated depending on the distribution of pedestrians, giving a dynamic route choice (Kretz, 2009; Kretz et al., 2011a).

The walking behavior at the operative level is determined by the SFM, with the preferred force given by Equation (2.1), and the dynamics given by Equations (2.1) to (2.4).

The version of $b$ implemented is the symmetric elliptical specification used by A. Johansson et al. (2007),

$$
b=\frac{1}{2} \sqrt{\left(r_{i j}+\left\|\mathbf{r}_{i j}+\dot{\mathbf{r}}_{i j} T\right\|\right)^{2}-\left(\dot{r}_{i j} T\right)^{2}},
$$

where $\mathbf{r}_{i j}$ is the position of the affected pedestrian $i$ relative to the affecting pedestrian $j$ and $T$ is a model parameter determining the anticipation time of the pedestrians.

The anisotropic weights are of the form proposed by Helbing et al. (2005),

$$
w\left(\varphi_{i j}\right)=\lambda+(1-\lambda) \frac{1+\cos \varphi_{i j}}{2},
$$

where $\lambda$ is a parameter controlling the strength of the anisotropy, and $\varphi_{i j}$ is the angle between the looking direction of the affected pedestrian and the direction to the affecting pedestrian.

\subsection{Calibration of the SFM}

The SFM has a large number of parameters which can be classified according to the force to which they are related.

First, there are the parameters of the preferred force, the force guiding the pedestrian toward its destination, Equation (2.1). This term in- 
cludes the relaxation time $\tau$, which specify the time scale of the adaptation of the velocity to the preferred velocity.

The value of the relaxation time, as the values of all the parameters, needs to be estimated from observations of pedestrian behavior. No quantitative microscopic data were available when the SFM was proposed by Helbing and Molnár (1995), but they report that the value of $0.5 \mathrm{~s}$ gives simulation results that qualitatively agrees with observations.

Through a controlled experiment with pedestrians told to accelerate from stand still to their preferred speed at a signal, Ma et al. (2010) verify that Equation (2.1) gives an accurate description of the acceleration process of pedestrians. They also report an estimate of the value of $\tau$ for the observed pedestrians with a mean of $0.71 \mathrm{~s}$ and a standard deviation of $0.1 \mathrm{~s}$, indicating that the observed population is rather homogeneous with respect to the linear acceleration behavior. Also Moussaïd et al. (2009) reports on a similar experiment with a mean observed relaxation time of $0.54 \mathrm{~s}$ and a standard deviation of only $0.05 \mathrm{~s}$. However, both studies are based on observations of controlled experiments with relatively small populations of observed pedestrians, 20 males and 20 females in the study by Moussaï et al. (2009), and 15 males and 5 females in the study by Ma et al. (2010). Furthermore, the subjects were not representative of the general population with respect to age; the participants were between 18 years and 30 years in the study by Moussaïd et al. (2009) and between 20 years and 24 years in the study by Ma et al. (2010). Also, the subjects were told what to do, which potentially could affect their behavior.

There are also results on the value of the relaxation time from calibration studies aimed at estimating several of the parameters of the model simultaneously through an optimization procedure. A. Johansson (2009) reports values of the relaxation time between $0.55 \mathrm{~s}$ and $0.62 \mathrm{~s}$, depending on the exact form of the other components of the model. This calibration is based on data both from real pedestrian traffic, and a controlled experiment. A similar study is reported by Zanlungo et al. (2011), who also compare various versions of the model, and ar- 
rive at values of the relaxation time between $0.2 \mathrm{~s}$ and $1.19 \mathrm{~s}$ depending on the form of the other components of the model. The data underlying this study is from a controlled experiment with 8 pedestrians. A similar method as used in these two studies is used in Paper IV of this thesis, resulting in a value of the relaxation time of $0.62 \mathrm{~s}$ or $0.72 \mathrm{~s}$ depending on if data from the morning or the afternoon was used. The calibration in Paper IV is based on data from real pedestrian traffic at a public transport interchange station consisting of more than three thousand observed pedestrians. However, the controlled experiments mentioned above have the advantage that they consider a situation where the behavior of the model is dependent on only the relaxation time and the preferred speed, which significantly simplifies the analysis.

As can be seen from the values of the relaxation time obtained in the various studies reviewed above, most of them, with the exception of some of the results by Zanlungo et al. (2011), are between $0.5 \mathrm{~s}$ and $0.75 \mathrm{~s}$. Thus, for real world applications, it is presently reasonable to consider this interval as an optimistic estimate of the uncertainty of the value of the relaxation time, and thus include simulations using values at least as extreme as the endpoints of the interval in the sensitivity analysis of the simulation outputs.

However, as discussed in Paper III of this thesis, values this high lead to significant outward drift in curves, which seems to be inconsistent with observations of pedestrians moving through curves, as presented in the paper. See Paper III for details and Section 3.4 for further discussion.

The preferred force also includes the preferred velocity. The magnitude of the preferred velocity, the preferred speed $v_{i}^{\mathrm{p}}$, is here seen as a parameter. The two controlled experiments mentioned above also obtained estimates of the preferred speed. Moussaïd et al. (2009) report a mean preferred speed of $1.29 \mathrm{~m} / \mathrm{s}$ with a standard deviation of $0.19 \mathrm{~m} / \mathrm{s}$, and Ma et al. (2010) a mean of $1.51 \mathrm{~m} / \mathrm{s}$ with a standard deviation of $0.15 \mathrm{~m} / \mathrm{s}$. However, the free flow speed of pedestrian flows has been measured in a large number of studies, see Daamen (2004) for a review, but usually focusing on just the mean value, not the full distribution. 
Paper IV of this thesis is concerned with how the preferred speed distribution can be measured and how uncertain the estimates are.

The force representing the social interactions, $\mathrm{F}_{i j}$, includes the force strength $F$, the range scale $\sigma$, and the anticipation time $T$. All these parameters are hard to observe directly and a given behavior can be reproduced by a number of different combinations of values of these parameters. Due to this it seems that the most promising estimation method for these parameters is the type of optimization based method used by A. Johansson (2009), Zanlungo et al. (2011), and also in Paper IV of this thesis. A. Johansson (2009) reports that the force strength and range are highly interdependent, and that no choice of the values of this pair of parameters gives a superior fit of the model, but rather that there is a connected set of values in parameter space that gives approximately the same fit. This implies that in many of the interactions in the data set which the calibration is based upon, a weak force can be compensated by a long range to give a behavior similar to a stronger force with a shorter range. However, in principle these two situations should be possible to distinguish, provided a sufficient amount of data, including sufficiently varied situations, are available.

Comparing the values of the force strength, force range scale, and the anticipation time obtained in the three studies mentioned above for a specific version of the model, reveals a similar variation to that of the relaxation time. The force strength varies between $0.58 \mathrm{~m} / \mathrm{s}^{2}$ and $0.8 \mathrm{~m} / \mathrm{s}^{2}$, the range scale varies between $0.45 \mathrm{~m}$ and $0.62 \mathrm{~m}$, and the anticipation time varies between $1.3 \mathrm{~s}$ and $2.0 \mathrm{~s}$. These variations are for the same specification of the social interaction force, and for similar calibration methods, so the main cause for the differences is probably the characteristics of the underlying data sets. The conclusion for practical applications is the same as for the relaxation time: these intervals can be seen as optimistic estimates of the uncertainty in the calibration, and should thus be included in the sensitivity analysis of any simulation outputs. Paper V of this thesis investigates the uncertainties of the outputs of simulations related to these, and other, uncertainties in the input to simulations. 
There are also parameters analogous to the force strength and range scale in the various specifications of the physical interaction force $\mathbf{F}_{i j}^{\mathrm{ph}}$ and the obstacle force $\mathrm{F}_{i o}^{\mathrm{ob}}$, however, the author of this thesis is not aware of any study aimed at finding suitable values of these parameters. 


\section{Chapter 3}

\section{The present thesis}

The purpose of this thesis is to advance the capabilities of pedestrian microsimulation toward a level at which it can be reliably applied for quantitative analysis by practitioners in the field. Quantitative analysis here refers to analysis based on predictions in terms of quantitative measures of various aspects of the traffic that reveal both the average behavior of the system as well as its expected degree of variation.

The focus of the research presented in this thesis is on the Social Force Model (SFM), but most of the results are either directly valid for, or generalizable to, force based models in general.

A number of advances to the capabilities of pedestrian microsimulation are made in the five included papers. Some of the advances are critical for quantitative use of pedestrian microsimulation in some situations: without properly defined performance measures, discussed in Paper I, quantitative analysis and evaluation is impossible, and without waiting models, such as those proposed in Paper II, simulations of a public transport station is only possible under very specific circumstances. Other advances are harder to measure the importance of; the problems connected to the relaxation time discussed in Paper III and those connected to observing the preferred speed distribution discussed in Paper IV, may be very important in some scenarios while 
not being problematic at all in others. However, since it is hard to tell which scenarios are affected, a proper understanding of the potential problems is important to be able to confidently apply pedestrian simulation to any scenario.

\subsection{Contributions}

The present thesis makes the following contributions,

- Proposes a set of local performance measures, with a range scale equal to the range of interactions between pedestrians.

- Demonstrates that the proposed measures provide information on different aspects of the traffic state.

- Demonstrates, using the local measures, that the SFM, in the case of perpendicularly intersecting unidirectional flows, predicts negative delays downstream of the intersection and problematic behavior in the downstream corner. This both demonstrates the power of the proposed measures, and reveals that the model may have problems related to the relaxation time.

- Implements and documents a simulation platform for pedestrian traffic, providing insights into details and assumptions underlying the application of pedestrian microsimulation.

- Extends the SFM with a waiting model, demonstrated to have relevant extreme cases for the value of its parameter, and proved to be stable and free from oscillations.

- Investigates the predictions made by the proposed waiting model, indicating that observations of the distribution of waiting pedestrians can be used to calibrate the model.

- Explores the role of the relaxation time in force based models, demonstrating a conflict between the models' abilities to describe linear acceleration and turning movements, both affected by the relaxation time, indicating that modification of the preferred force is needed for accurate reproduction of both behaviors. 
- Extends an existing calibration method, enabling it to obtain estimates of the preferred speed distribution, together with remaining parameters of the SFM.

- Compares the preferred speed distributions of morning and afternoon traffic at Stockholm Central Station, demonstrating that the speeds differ, and thus the preferred speed distribution cannot be assumed to be the same at different times of the day.

- Compares the speeds of pedestrians using mobile phones while walking and pedestrians not doing so, demonstrating that the difference is approximately equal to the difference between morning and afternoon.

- Compares sources of uncertainties in an application of pedestrian microsimulation to a case with unusually good availability of data indicating that further work on calibration is needed.

- Expands the understanding of force based models of pedestrian traffic and their potential for quantitative analysis.

\subsection{Delimitations}

Since the SFM is the dominating model used by practitioners, and the purpose of this thesis is to facilitate practical use of quantitative analysis based on microscopic simulation of pedestrian traffic, the research is delimited to only consider force based simulation models, with special focus on the SFM. However, there exist numerous other models, several of which may be more promising in the long run, but when the aim is to advance the tools available for practitioners within a few years, the SFM is the outstanding candidate.

Furthermore, this thesis is only concerned with simulation with the purpose of evaluating the quality of pedestrian traffic, that is, it is assumed that the pedestrians are walking with the purpose of transporting themselves to extract some utility at their destination. Thus, walking for leisure or exercise, or strolling around without a destination, is not included. Also, emergency situations that require accurate 
modeling of physical forces, or modeling of panic or severe stress, are excluded.

It is hard to overstate the importance of data on pedestrian behavior when developing and applying microscopic pedestrian simulation. However, data collection is costly. Due to limited resources, the amount of data collected as part of the research presented in this thesis is limited, which also limits the possible areas of investigation.

\subsection{Paper summaries}

The thesis contains five papers: the first proposes local performance measures for pedestrian traffic, the second extends the SFM to include waiting pedestrians, the third explores the many roles of the relaxation time parameter in force based models, the fourth examines the constancy of the preferred speed distribution of pedestrians, and the fifth presents a sensitivity analysis of a simulation of a part of Stockholm Central Station to find the most important potential sources of errors.

\section{Paper I: Local performance measures of pedestrian traffic}

With the purpose of avoiding artifacts of manual choices of aggregation areas for performance measures, Paper I presents a set of local performance measures of pedestrian traffic. The measures are constructed to quantify the performance of pedestrian traffic, and estimate the discomfort perceived by pedestrians, using microscopic simulation based on the SFM. The paper contributes to the literature by extending existing measures by incorporating quantities from the SFM to define a suitable scale of resolution of the measures, and to estimate the discomfort caused by pedestrian congestion. Furthermore, the paper expands the knowledge of the properties of the SFM by using the measures to reveal nontrivial predictions of the model.

The spatial scale of the measures is set to the range scale of the social force between pedestrians, which previous calibrations studies 
agrees is approximately $0.6 \mathrm{~m}$. The proposed measures are examined by performing simulations of simple pedestrian scenarios, two versions of bidirectional flow and crossing unidirectional flows, and analyzing the output using the measures. The analysis demonstrates that the different measures provide different information regarding the traffic situation, and also reveals that the model predicts negative delay rates downstream of an intersection in the scenario with crossing flows. Furthermore, the analysis indicates that the model may have some problems related to the coupling between the SFM and the route choice. These problems are investigated further in Paper III.

Finally the measures are applied for analyzing the simulation of the traffic at one of the platforms at Linköping Central Station.

The paper is coauthored with Anders Peterson and Andreas Tapani. The author of this thesis has contributed as the main author and by major involvement in the research planning, development of the measures, simulations, and analysis.

Paper I is published in

- Public Transport 6, 2014, pp. 159-183.

The content of Paper I has been presented at

- CASPT 12, Conference on Advanced Systems for Public Transport, Santiago, Chile, July 23-27, 2012.

Parts of the content of Paper I have been presented at

- Transportforum, Linköping, January 11-12, 2012.

\section{Paper II: Waiting pedestrians in the social force model}

Paper II extends the SFM to include waiting pedestrians with the purpose of enabling accurate modeling of public transport interchange stations and similar facilities where groups of waiting pedestrians may impede passing pedestrians. The contribution of the paper is a model, 
demonstrated to be stable and oscillation free, that in a natural way extends the SFM to include waiting behavior.

The proposed waiting model is based on setting the preferred velocity of the pedestrian in such a way that reasonable waiting behavior is produced. The behavior of the model is investigated for different values of its parameter, with special focus on the special cases corresponding to the extremes of the parameter value, treated in the paper as separate models. The produced waiting behavior is shown to span a large range of reasonable behaviors of waiting pedestrians and simulations are performed to indicate how the structure of the flow passing by waiting pedestrians, as well as the distribution of waiting pedestrians, are dependent on the specification of the model.

The paper is coauthored with Anders Peterson and Andreas Tapani. The author of this thesis has contributed as the main author and by major involvement in the research planning, modeling, simulations, and analysis.

Paper II is published in

- Physica A: Statistical Mechanics and its Applications 419, 2015, pp. 95-107.

Parts of the content of Paper II have been presented at

- Nationell konferens i transportforskning, Stockholm, October 1819, 2012,

- Transportforum, Linköping, January 9-10, 2013,

- Nationell konferens i transportforskning, Göteborg, October 2223, 2013,

- Transportforum, Linköping, January 8-9, 2014. 


\section{Paper III: The many roles of the relaxation time parameter in force based models of pedestrian dynamics}

The purpose of Paper III is to enable future improvements of force based models by exploring the many roles of the relaxation time of the adaptation to the preferred velocity. The main contribution of the paper is a demonstration that no choice of the value of the relaxation time is consistent with both previous observations of linearly accelerating pedestrians and new observations of turning pedestrians.

The value of the relaxation time affects both the adaptation to the preferred speed in linear motion and the adaptation to a changing preferred velocity when the preferred path is curved. Thus, the ability of unhindered simulated pedestrians to perform sharp turns around corners is directly related to their acceleration profile when starting from standstill and accelerating to their preferred speed.

By using trajectory data from a walking event in the Netherlands and comparing with previous studies of linear acceleration, it is found that using the value of the relaxation time obtained from the linear acceleration studies would lead to larger turning radii than observed in the data from the Netherlands. Furthermore, it is demonstrated that, in general, simulated pedestrians will not be able to follow their preferred paths. Thus, there are significant problems with the interpretation and observation of the preferred velocities of pedestrians.

This shows that the simplest form of the force attracting pedestrians to their destination, which is common to most force based models, needs to be modified if more accurate predictions of pedestrian traffic is desired.

The paper is coauthored with Dorine Duives, Winnie Daamen, and Serge Hoogendoorn. The author of this thesis has contributed as the main author and by major involvement in the research planning, simulations, and analysis.

Paper III is published in

- Transportation Research Procedia 2, 2014, pp. 300-308. 
The content of Paper III has been presented at

- PED2014, The Conference on Pedestrian and Evacuation Dynamics, Nootdorp, Netherlands, October 22-24, 2014,

- Transportforum, Linköping, January 8-9, 2015.

\section{Paper IV: The preferred speed distribution in microscopic simulation of pedestrian traffic}

Paper IV compares the preferred speed distributions at a location at two different times of the day with the purpose of testing the common assumption that the preferred speed distribution is the same at all times of the day. The advantage of this assumption is that it allows users of pedestrian simulation to measure the preferred speed distribution at free flow conditions, which typically occur at a different time of the day than what is interesting to simulate, and then use it to simulate congested conditions at another time of the day. The results are important for practical applications since they imply that there is a need to consider an uncertainty in the preferred speed distribution when performing simulations.

Speed distributions are extracted from trajectory data from Stockholm Central Station using a method based on calibrating the SFM by adjusting the individual preferred speeds of the observed pedestrians. This method enables the extraction of preferred speeds, in the sense of the SFM, also under slightly congested situations. Also the remaining parameters of the model are estimated from the morning and afternoon data separately. Both the method and the found speed distributions and parameter values constitute contributions to the literature.

The result of the comparison indicates that the preferred speed varies during the day, which implies that a preferred speed distribution obtained under free flow conditions at one time of day may be a poor estimate of the preferred speed distribution at the time that should be simulated. Using the same method, the preferred speeds of different pedestrian categories are compared, indicating differences of approxi- 
mately the same size as the difference between different times of the day.

The paper is coauthored with Malin Lagervall, Sandra Samuelsson, Anders Peterson, and Andreas Tapani. The author of this thesis has contributed as the main author and by major involvement in the research planning, method development, and analysis.

Paper IV is a working paper.

Parts of the content of Paper IV have been presented at

- Young Researchers Seminar, Rome, Italy, June 17-19, 2015,

- Nationell konferens i transportforskning, Karlstad, October 2122, 2015 .

\section{Paper V: Sensitivity of pedestrian microsimulations}

The purpose of Paper V is to find the most important sources of uncertainty in microscopic simulation of pedestrian traffic, among a subset of the inputs and parameters for which estimation of the uncertainty is feasible. This indicates for practitioners which inputs are most important to measure accurately, and also, for researchers, in which areas future research may improve the accuracy of the model. To find the most important sources of uncertainty, Paper V presents a sensitivity analysis of a simulation of the pedestrian traffic at a simplified version of the lower hall of Stockholm Central Station.

The uncertainties of the parameter values are optimistically estimated by the difference between the values obtained in Paper IV through calibrations based on morning and afternoon data. The uncertainty of the simulation output due to the uncertainties in the parameters is much larger than corresponding uncertainties from the remaining considered inputs. This is an indication that further research on calibration, and more data to calibrate against, is needed.

The paper is coauthored with Anders Peterson and Andreas Tapani. The author of this thesis has contributed as the main author and by major involvement in the research planning, simulations, and analysis.

Paper V is a working paper. 


\subsection{Future research}

This thesis advance the capabilities of pedestrian microsimulation toward a level at which it can be reliably applied for quantitative analysis by practitioners in the field. However, several problems remain to be solved before microsimulation of pedestrian traffic becomes a reliable quantitative tool for practitioners.

One of the measures introduced in Paper I aims to estimate the discomfort of pedestrians by using the forces from the SFM. This may be stretching the force concept over its borders of applicability, so a behavioral study comparing the discomfort according to the measure with statements of pedestrians walking in a corresponding real situation would be an interesting test of the measure.

The proposed measures are local in space and aggregates features of the traffic situation that are connected due to interactions between pedestrians. However, pedestrian traffic typically varies not only in space but also in time. Thus, a corresponding aggregation should be done in time, taking into account how pedestrians perceive long periods of congestion contra short ones. For delay and density it is motivated to just average over the whole simulation since these are well defined quantities of which the mean is relevant, but for measuring the perceived discomfort this method may oversimplify the preferences of the pedestrians. It may be the case that the perceived discomfort is nonlinearly dependent on the duration of a situation with high discomfort density rate, as defined in Paper I. This problem is closely related to the value of time used in cost benefit analysis of traffic systems.

Behaviorally oriented research may contribute considerably also to other problems considered in this thesis. Investigations into how people reason around their choice of waiting position, route choice, and interaction with other pedestrians, could help improve the models.

Dynamic route choice of pedestrians has been an active field of research for several years. Some kind of dynamic alteration of the preferred velocity depending on the distribution of pedestrians ahead seems promising, but verification is hampered by the difficulties of obtaining data on the relevant scale, although innovative techniques are being 
developed to overcome this issue (Kretz et al., 2011b).

A corresponding dynamic model for the choice of (initial) preferred waiting position in relation to various objects of interest, for example information signs, platform edges, shelter, etc., would be an interesting topic for future studies. That is, how is the choice of waiting position dependent on the distribution of already present waiters, the structure of the passing flows, and the geometry of the waiting area. However, investigating this before a standard model of dynamic route choice is available may not be advisable since the two models need to be consistent.

The results of Paper III indicate that there is no value of the relaxation time that is consistent with observations of turning pedestrians and linearly accelerating pedestrians. One way to solve this problem could be, as mentioned in the paper, to treat acceleration in the direction of movement differently from acceleration perpendicular to it, as proposed by Hoogendoorn and Bovy (2003). This will introduce another parameter into the model. However, the results also indicate that a pedestrian will never attain its preferred path, making the interpretation of the preferred velocity field problematic.

One natural possibility is to introduce anticipation also into the calculation of the preferred force,

$$
\tilde{\mathbf{F}}=\frac{1}{\tau}\left(\mathbf{v}_{i}^{\mathrm{p}}(\mathbf{x}+\Delta \mathbf{x})-\dot{\mathbf{x}}_{i}\right),
$$

where $\Delta \mathbf{x}$ is a small displacement in the direction of movement of the pedestrian, either a fixed distance or based on the present speed. Preliminary results indicate that $\Delta \mathbf{x}=\tau \dot{\mathbf{x}}_{i}$ eliminates drifting in smooth curves. Further analysis is however needed to confirm this and to guarantee that this does not alter other desirable behavior of the model.

Dynamic route choice is also closely related to the relaxation time problems, since it will introduce a temporally varying preferred velocity, and the relaxation time will dictate the adaptation to these changes, further complicating the role of the relaxation time. Thus, dynamic route choice stands out as potentially the most important modeling problem in microsimulation of pedestrian traffic not treated in this the- 
sis.

One of the main application areas focused on in this thesis has been public transport interchange stations. However, there are parts of such stations where pedestrians interact with other modes of transport, and for a complete view of the performance of a station, accurate modeling of these interactions is important, and thus constitute an interesting topic of future research.

One of the simplest forms of this interaction occurs when a public transport vehicle arrives at its stop. A common reaction of a waiting group is to align in relation to the positions of the doors of the arriving vehicle; this behavior may be important to model correctly since depending on the structure of the resulting group, it may hinder passing pedestrians more or less. This can be seen as an important special case of the choice of waiting position mentioned above, but pose special problems due to the dynamic situation. Also, when the vehicle is about to leave, the driver may decide to wait for pedestrians on their way to the vehicle. One problem with modeling both of these vehiclepedestrian interactions is that they are likely to vary significantly between locations, increasing the amount of data needed, and possibly weakening the predictive power of a model of the behavior.

A more complicated example of interactions between public transport vehicles and pedestrians is when pedestrians walk in the same area as for examples buses are driving in. This leads to a situation similar to the shared space concept, for which models recently have been proposed (Schönauer et al., 2012; Rudloff et al., 2013; Anvari et al., 2013; Anvari et al., 2014, 2016). Specializing these models to the case of buses and calibrating them for this specific environment is an interesting topic of future research.

Much of the research in this thesis has been motivated by the need to simulate the pedestrian traffic at public transport interchange stations. Other examples of applications for which microsimulation could be interesting includes the compromise between flow efficiency and commercial interests on heavily trafficked pedestrian streets. Shops, restaurants, etc., may want to use parts of a street for business pur- 
poses, which also may cause a subset of the passing pedestrians to stop and thus cause delays for the remaining passing pedestrians. The traffic efficiency effects of this would be interesting to investigate using microsimulation. However, this use case is only interesting if the considered street is densely trafficked and a large fraction of the pedestrians does not receive any utility from the activities along the street.

Even though several methods for calibrating pedestrian microsimulation models have been proposed and used, there are still few studies investigating the performance of these methods. An interesting topic of future research is therefore to evaluate and compare proposed calibration methods, both using real and synthetic data. This could also lead to better estimates of how uncertain the results of simulations are. 



\section{Bibliography}

Anvari, B., Knoop, V. L., Daamen, W., Hoogendoorn, S. P., and Bell, M. G. H. (2013). "Shared Space Modeling Based on Social Forces and Distance Potential Field". In: Pedestrian and Evacuation Dynamics 2012.

Anvari, B., Bell, M. G., Angeloudis, P., and Ochieng, W. Y. (2014). "Longrange collision avoidance for shared space simulation based on social forces”. Transportation Research Procedia 2, pp. 318-326.

Anvari, B., Bell, M. G., Angeloudis, P., and Ochieng, W. Y. (2016). "Calibration and Validation of a Shared Space Model: Case Study". Transportation Research Record: Journal of the Transportation Research Board (2588), pp. 43-52.

Daamen, W. (2004). "Modelling Passenger Flows in Public Transport Facilities". PhD thesis. TU Delft. ISBN: 90-407-2521-7. URL: http: //resolver.tudelft.nl/uuid: e65fb66c-1e55-4e63-8c495199d40f60e1.

Dijkstra, E. W. (1959). "A note on two problems in connexion with graphs”. Numerische mathematik 1.(1), pp. 269-271.

Gipps, P. and Marksjö, B. (1985). "A micro-simulation model for pedestrian flows”. Mathematics and Computers in Simulation 27.(2), pp. 95105. DOI: $10.1016 / 0378-4754$ (85) 90027-8.

Helbing, D., Buzna, L., Johansson, A., and Werner, T. (2005). "Selforganized pedestrian crowd dynamics: Experiments, simulations, 
and design solutions". Transportation Science 39.(1), pp. 1-24. DoI: $10.1287 / \operatorname{trsc} .1040 .0108$.

Helbing, D., Farkas, I., and Vicsek, T. (2000). "Simulating dynamical features of escape panic". Nature 407, pp. 487-490. DOI: 10 . 1038 / 35035023. arXiv: cond - mat / 0009448v1 [cond-mat.stat-mech].

Helbing, D. and Molnár, P. (1995). "Social force model for pedestrian dynamics". Physical Review E: Statistical, nonlinear and soft matter physics 51, pp. 4282-4286. DOI: 10.1103/PhysRevE . 51 . 4282. arXiv: cond-mat/9805244.

Hirai, K. and Tarui, K. (1975). "A Simulation of the behavior of a crowd in panic". In: Proceedings of the 1975 International Conference on Cybernetics and Society, pp. 409-411.

Hoogendoorn, S. and Bovy, P. (2003). "Simulation of pedestrian flows by optimal control and differential games". Optimal Control Applications and Methods 24, pp. 153-172. DOI: 10.1002/oca.727.

Hoogendoorn, S. and Bovy, P. (2004). "Pedestrian route-choice and activity scheduling theory and models". Transportation Research Part B: Methodological 38.(2), pp. 169-190. DoI: 10.1016/S01912615 (03) 00007-9.

Johansson, A. (2009). "Data-Driven Modeling of Pedestrian Crowds". PhD thesis. Technische Universität Dresden. URL: http://nbnresolving.de/urn:nbn:de:bsz:14-qucosa-20900.

Johansson, A., Helbing, D., and Shukla, P. K. (2007). "Specification of the social force pedestrian model by evolutionary adjustment to video tracking data". Advances in Complex Systems 10.(SUPPL. 2), pp. 271288. DOI: 10.1142 / S0219525907001355. arXiv: 0810.4587 [physics.soc-ph].

Johansson, F. (2013). Pedestrian traffic simulation platform. VTI notat (16-2013). Swedish National Road and Transport Research Institute, Linköping. URL: http://www.vti.se/en/publications/. 
Johansson, F., Peterson, A., and Tapani, A. (2014a). "Local performance measures of pedestrian traffic”. Public Transport 6, pp. 159-183. DoI: 10.1007/s12469-013-0081-9.

Johansson, F., Duives, D., Daamen, W., and Hoogendoorn, S. (2014b). "The many roles of the relaxation time parameter in force based models of pedestrian dynamics". Transportation Research Procedia 2. The Conference on Pedestrian and Evacuation Dynamics 2014 (PED 2014), 22-24 October 2014, Delft, The Netherlands, pp. 300-308. Dor: $10.1016 / j$.trpro. 2014.09.057.

Johansson, F., Lagervall, M., Samuelsson, S., Peterson, A., and Tapani, A. (2016a). The preferred speed distribution in microscopic simulation of pedestrian traffic. Working paper.

Johansson, F., Peterson, A., and Tapani, A. (2015). "Waiting pedestrians in the social force model". Physica A: Statistical Mechanics and its Applications 419, pp. 95-107. DOI: 10.1016/j . physa.2014.10. 003.

Johansson, F., Peterson, A., and Tapani, A. (2016b). Sensitivity of pedestrian microsimulations. Working paper.

Kretz, T. (2009). "Pedestrian traffic: on the quickest path". fournal of Statistical Mechanics: Theory and Experiment 2009.(03), P03012. DOI: doi: 10.1088/1742-5468/2009/03/P03012. arXiv: 0901.0170 [physics.soc-ph].

Kretz, T., Große, A., Hengst, S., Kautzsch, L., Pohlmann, A., and Vortisch, P. (2011a). "Quickest paths in simulations of pedestrians". Advances in Complex Systems 14.(05), pp. 733-759. DOI: 10.1142/ S0219525911003281. arXiv: 1107.2004 [physics.soc-ph].

Kretz, T., Hengst, S., Roca, V., Arias, A. P., Friedberger, S., and Hanebeck, U. D. (2011b). "Calibrating dynamic pedestrian route choice with an extended range telepresence system". In: Computer Vision Workshops (ICCV Workshops), 2011 IEEE International Conference on. IEEE, pp. 166-172. 
Lozano-Pérez, T. and Wesley, M. A. (1979). "An algorithm for planning collision-free paths among polyhedral obstacles". Communications of the ACM 22.(10), pp. 560-570. DOI: 10.1145/359156.359164.

Ma, J., Song, W., Fang, Z., Lo, S., and Liao, G. (2010). "Experimental study on microscopic moving characteristics of pedestrians in built corridor based on digital image processing". Building and Environment 45.(10), pp. 2160-2169. DoI: 10.1016/j . buildenv . 2010.03.015.

Michon, J. A. (1985). "A critical view of driver behavior models: what do we know, what should we do?" In: Human behavior and traffic safety. Springer, pp. 485-524.

Moussaï, M., Helbing, D., Garnier, S., Johansson, A., Combe, M., and Theraulaz, G. (2009). "Experimental study of the behavioural mechanisms underlying self-organization in human crowds". Proceedings of the Royal Society B: Biological Sciences 276.(1668), pp. 2755-2762. DOI: $10.1098 / \mathrm{rspb} .2009 .0405$.

Rudloff, C., Schönauer, R., and Fellendorf, M. (2013). "Comparing calibrated shared space simulation model with real-life data". Transportation Research Record: Journal of the Transportation Research Board (2390), pp. 44-52.

Schönauer, R., Stubenschrott, M., Huang, W., Rudloff, C., and Fellendorf, M. (2012). "Modeling Concepts for Mixed Traffic: Steps Toward a Microscopic Simulation Tool for Shared Space Zones". Transportation Research Record: Journal of the Transportation Research Board (2316), pp. 114-121.

Sethian, J. A. (1996). "A fast marching level set method for monotonically advancing fronts". Proceedings of the National Academy of Sciences 93.(4), pp. 1591-1595. URL: http://www . pnas .org/content/93/ 4/1591.full.pdf+html.

Stroustrup, B. (1984). The $C++$ programming language. Tech. rep. Bell Lab. URL: http://cds.cern.ch/record/169940/files/cer000081326.pdf. 
Stroustrup, B. (2013). The C++ programming language. Pearson Education.

The Qt Company Ltd. (2016). Qt. URL: http://doc.qt.io/.

Zanlungo, F., Ikeda, T., and Kanda, T. (2011). "Social force model with explicit collision prediction”. Europhysics Letters 93.(6), p. 68005. DOI: $10.1209 / 0295-5075 / 93 / 68005$. 



\section{Papers}

The articles associated with this thesis have been removed for copyright reasons. For more details about these see:

http://urn.kb.se/resolve?urn=urn:nbn:se:liu:diva-133330 